\title{
Kontribusi Recive Servis, Dig, Cover dan Toss Pemain Libero dalam Pertandingan Final SEA GAMES 2019
}

\author{
Sujarwo, Arif Purnomo \\ Jurusan Ilmu Keolahragaan, Fakultas Ilmu Keolahragaan, \\ Universitas Negeri Yogyakarta, Indonesia
}

Diterima: 7 April 2020. Direvisi: 18 April 2020. Disetujui: 2 Juli 2020

\begin{abstract}
Abstrak Tujuan penelitian ini adalah untuk mengetahui seberapa besar kontribusi recive servis, dig, cover dan toss pemain libero dalam pertandingan bola voli. Metode penelitian menggunakan penelitian deskriptif kuantitatif dengan teknik observasi dan match analisis pada pertandingan final bola voli putra indoor SEA GAMES 2019. Instrumen dalam penelitian ini adalah lembar observasi yang dinilai oleh dua orang ahli, yaitu ahli bola voli dan ahli tes dan pengukuran. Subjek dalam penelitian ini adalah dua orang libero tim nasional bola voli indoor Indonesia. Hasil penelitian menunjukkan bahwa pada set pertama libero 1 berkontribusi dalam recive servis, dig, cover dan toss sebesar: $38.6 \%$. Set kedua libero 1 berkontribusi: $26.2 \%$. Pada set kedua libero 2 berkontribusi sebesar: $16.3 \%$. Pada set ketiga libero 2 berkontribusi sebesar: $52.1 \%$. Kesimpulan dalam penelitian ini bahwa kontribusi kemampuan libero sangat menentukan dalam keberhasilan tim dalam melakukan serangan maupun bertahan, baik kemampuan recive servis, dig, cover dan toss. Rekomendasi peneliti hendaknya pelatih melatih libero dengan kondisi sedekat mungkin dengan kondisi sebenarnya di lapangan. Kesalahan yang dilakukan libero di lapangan hendaknya diulang-ulang dibenahi dan diberikan solusi atau pembetulan baik konsep maupun teknik.
\end{abstract}

Kata Kunci: kontribusi, recive servis, dig, cover, toss, libero.

Abstract Purposed of this study was to determine the contribution of recive servis, dig and toss libero players in volleyball matches. The research method was used quantitative descriptive research with observation and match analysis techniques in the SEA GAMES 2019 indoor men's volleyball final match. The study's instrument was the observation sheet assessed by two experts, namely, volleyball expert, test and measurement expert. Subjects in this study were two Indonesian national volleyball national team libero. Results showed that in the first set libero number 1 contributed to the recive service, dig and toss by: $38.6 \%$. The second set of libero number 1 provided: $26.2 \%$. In the second set of libero number 2 participated: $16.3 \%$. In third set, libero number 2 contributed: $52.1 \%$. The conclusion in this study is that the contribution of Libero's ability was crucial to the success of the team in attack and defense, both the ability to recive service, dig, cover and toss. Common researchers' recommendation should be that the trainer train libero with conditions as close as possible to the field's actual requirements. A libero made mistakes in the area should be repeated addressed and given a solution or correction of both concepts and techniques.
Keywords: contribution, recive servis, dig, cover, toss, libero

\section{PENDAHULUAN}

Libero merupakan salah satu pemain kunci dalam permainan bola voli dalam upaya menyerang maupun bertahan. Kehadiran libero diharapkan untuk mengembangkan kemampuan bertahan tim (Mesquita, et al: 2007). Perkembangan permainan bola voli saat ini libero bisa menggunakan dua orang dalam satu tim. Hal ini sangat membantu tim dalam upaya memperkuat pertahanan dan juga recive servis agar bola voli semakin menarik untuk dilihat, semakin banyak bola di udara, sesuai dengan motto FIVB yaitu "keep the ball flying". Libero memiliki tugas yang cukup besar, di antaranya: melakukan recive servis, dig, cover, dan toss, dari smash kawan maupun lawan. Tugas libero sangat besar dalam defense dibanding pemain lain (Rentero, et al: 2015).

Parameter bagus dan tidak kemampuan atau skill seorang libero hendaknya dilihat dari kemampuan recive servis baik pasing bawah maupun atas dan defense. Seorang libero yang bagus hendaknya memiliki kemampuan seperti berikut: 1) kemampuan mata yang jeli melihat dan membaca pergerakan bola baik dari lawan maupun tim sendiri, baik dari servis lawan maupun dari smash lawan; 2) pergerakan perpindahan yang bagus/menutup atau menguasai daerah serang dan bertahan, melakukan transisi dari recive servis, kemudian cover, kemudian defense; 3) kemampuan reaksi seluruh tubuh yang bagus; 4) memiliki daya juang yang tinggi, 5) tidak memiliki rasa takut terhadap smash atau servis lawan. Untuk tim elit atau nasional bahkan profesional libero harus memiliki kemampuan lebih, karena tuntutan skill untuk elit atlet dengan kemampuan 
servis jump smash dan smash yang kuat dan cepat sehingga libero harus mampu menerimanya dengan baik (Merghes and Gradinaru: 2014).

Koordinasi defense dalam permainan bola voli sebaiknya dikoordinasi oleh libero, karena libero lebih menguasai daerah lapangan. Libero merupakan posisi yang unik dalam permainan bola voli yang memberikan kontribusi terhadap pertahanan tim. Pemain ini menggantikan pemain yang kemampuan recive servis kurang, dalam spesialisasi biasanya middle bloker atau center blok yang digantikan oleh libero. Libero saat mulai permainan (play on) biasanya memposisikan diri di posisi lima agar lebih efektif dalam menguasai pertahanan. Libero merupakan pemain khusus untuk bertahan di permainan bola voli. Sesorang yang memiliki kualitas recive servis bagus terarah ke tosser atau pengumpan. Libero menggantikan pemain yang di belakang tidak memiliki kemampuan defense yang bagus, atau untuk mengistirahatkan pemain. Berikut tujuan dan moment atau waktu yang tepat dalam mengganti libero, atau dasar pertimbangan mengganti pemain dengan libero: 1) untuk penerimaan bola servis yang baik; 2) untuk mengistirahatkan pemain yang diandalkan; 3) untuk meningkatkan pertahanan daerah belakang; 4) pada saat point kritis dalam pertandingan untuk melebarkan jarak point dengan lawan (Merrett: 2004).

Strategi pelatih bola voli dengan sistem permainan bola voli dengan rally point, maka cenderung menggunakan spesialisasi pemain, khususnya untuk libero pelatih akan mengoptimalkan kemampuannya untuk recive servis, dan defense (Miller: 2005). Tujuan defense dalam permainan bola voli adalah untuk mengeliminasi serangan lawan dan berusaha menjaga agar bola tidak mudah jatuh ke lapangan tim, libero sangat berperan dalam hal defense ini, berada di posisi lima dalam lapangan bola voli, karena dominasi serangan smash lawan mengarah ke posisi lima (McKeever, et al: 2018). Berikut konsep kemampuan yang harus dimiliki oleh libero, di antaranya:

\section{Recive Servis}

Merupakan kemampuan dalam menerima bola pertama dari servis lawan. Teknik ini harus dikuasai oleh semua pemain dalam bola voli, namun utamanya adalah: libero, dan open hitter atau open smasher. Karena mereka bertiga sebagai recive serve untuk menerima bola pertama dari servis lawan. Sedangkan setter, midl- le bloker, dan opposite bertugas masing-masing fokus menyerang. Open hitter atau open smasher tugas pertamanya adalah melakukan recive servis, kemudian baru fokus menyerang. Recive servis bagi tim yang melakukannya merupakan kesempatan pertama untuk merancang sistem serangan dan memposisikan tim tersebut untuk mencetak point. Recive servis bagus maka toser dengan mudah akan membagi bola kepada smasher dan membuat atau mengecoh blok tidak hanya berfokus pada salah satu smasher saja (Schmidt: 2016). Posisi arah bola hasil recive servis diupayakan ke arah setter lambungannya, namun apabila servis lawan sulit maka cukup dilambungkan bolanya di atas garis tiga meter agar setter dengan mudah mendekati bola dan kemudian mengatur strategi.

\section{Dig}

Kemampuan mengambil bola rendah baik dengan satu tangan maupun dua tangan untuk menyelamatkan bola dari serangan lawan baik smash, maupun tip lawan. Dig ini perlu sering dilatihkan juga karena biasanya atlet sangat malas untuk menekuk lutut ataupun mengambil sikap posisi rendah di dalam lapangan. Dig merupakan kemampuan yang setiap pemain dapat melakukannya namun memerlukan latihan yang banyak, berikut langkah-langakh melakukan dig, di antaranya: 1) pemain mengambil posisi siap dengan kaki agak sedikit lebar kemudian bahu condong ke depan siap untuk bergerak ke depan; 2) posisi rendah dekat dengan lantai lapangan; 3) memposisikan tangan selalu di depan dan jauh dari badan; 4) dia memposisikan kedua siku seperti pasing bawah, namun gerakan perkenaan dengan bola seperti mencangkul/dig dari bawah ke atas; 5) menjaga kedua lengan dekat dengan badan; dan 6) melakukan gerakan lanjutan agar kekuatan dan kecepatan smash dapat tereduksi (Bach: 2009). Dig merupakan kemampuan pemain bola voli dalam menerima smash keras lawan pada posisi seperti pasing bawah (Roque and Hansen: 2012).

\section{Cover}

Kemampuan menutup atau mendukung serangan tim maupun blok tim, apabila terjadi back ball atau bola hasil smash atau tip teman kembali karena menyentuh blok lawan, dan juga tipuan smash lawan/bola tip dari lawan yang melewati blok teman kita. Cover ini juga harus sering dilatihkan karena mengasah feeling dan kejelian melihat lawan yang akan melakukan tip smash perlu banyak dilakukan dan 
Tabel 1. Instrumen analisis kemampuan libero

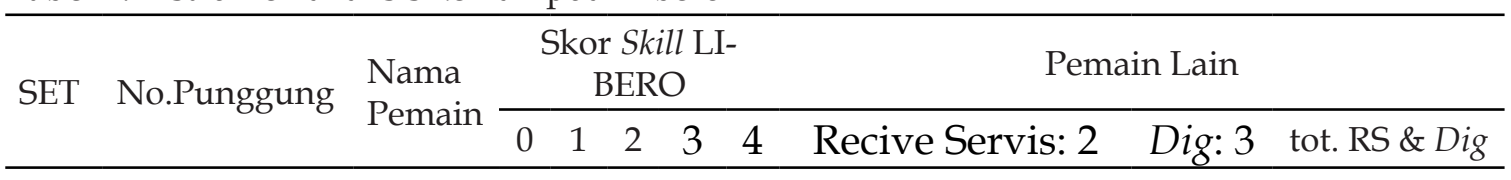

I

Jumlah Kontribusi Libero 1/2

II

Jumlah Kontribusi Libero 1/2

III

Jumlah Kontribusi Libero 1/2

Keterangan:

Skor:

0 : recive servis atau defense missed

1: recive servis atau defense tidak terarah ke setter atau sulit di toss ke smash

2: recive servis mudah ditoss oleh setter ke smash

3: dig dan cover bola bagus

4: melakukan toss ke smash bagus

disimulasikan dalam latihan. Cover merupakan kontak pertama hasil dari serangan teman sendiri yang terkena blok lawan (Hebert: 2014).

Toss

Kemampuan melakukan umpan ke smasher yang dimiliki oleh libero baik menggunakan pasing atas, kalo posisinya di belakang garis serang, dan pasing bawah apabila berada di depan garis serang. Kemampuan ini merupakan kemampuan yang tinggi tingkat kesulitannya, karena membutuhkan akurasi dan juga fokus memposisikan bola di depan smasher, seperti tugas setter atau pengumpan. Toss merupakan kemampuan memberikan umpan kepada smasher dalam melakukan serangan (Clemens and McDowell: 2012).

\section{METODE}

Penelitian ini menggunakan metode survei dengan lembar observasi dimana peneliti mengamati dua orang libero pada suatu pertandingan dan menganalisis pertandingan dengan instrumen yang disusun oleh peneliti sendiri yang di validasi oleh dua ahli yaitu ahli bola voli dan ahli tes dan pengukuran. Tabel 1 adalah instrumen yang digunakan dalam penelitian.

\section{HASIL DAN PEMBAHASAN}

Berdasarkan hasil penelitian menggunakan analisis pertandingan menunjukkan bahwa kontribusi kemampuan libero dalam recive servis, dig, cover dan toss dalam permainan bola voli pada even SEA GAMES 2019 di Philipina pada Tabel 2.

Tabel 2. Kontribusi libero dalam persen\%

\begin{tabular}{lcc}
\hline Nama Pemain & SET & Persentase \\
\hline \multirow{2}{*}{ Libero 1 } & set 1 & $38.6 \%$ \\
& set 2 & $26.2 \%$ \\
Libero 2 & set 2 & $16.3 \%$ \\
& set 3 & $52.1 \%$ \\
\hline
\end{tabular}

Hasil penelitian menunjukkan bahwa kontribusi libero 1 pada set pertama sebesar $38.6 \%$, terdiri atas kemampuan: mampu memenangkan pertandingan dengan skor: satu kali recive servis agak sulit di toss, dua kali recive servis bagus untuk di toss, dua kali mendapatkan defense dengan dig dan satu kali cover, dan dua kali melakukan toss untuk smasher dengan satu kali pasing bawah dan satu kali menggunakan pasing atas. Set pertama Indo- 
nesia mampu menang dengan skor 25 - 21 .

Pada set kedua point awal libero masih menggunakan libero 1 dengan kontribusi: $26.2 \%$, terdiri atas kemampuan: dua kali error recive servis, satu kali recive servis bagus untuk di toss, empat kali mendapatkan defense dengan dig, dan satu kali toss ke smasher dengan pasing bawah. Melihat error yang dilakukan pada recive servis maka pelatih menerapkan strategi mengganti libero dengan libero 2, dengan kontribusi pada set kedua: 16.3\%, dengan deskripsi kemampuan, sebagai berikut: tiga kali recive servis bagus mudah di toss, dan satu kali toss ke smasher dengan pasing bawah. Set kedua Indonesia masih menang meskipun terjadi nilai ketat deuce: $27-25$.

Pada set ketiga libero yang digunakan adalah libero 2 dengan pertimbangan tertentu menggunakan libero 2 dimana masih memiliki kondisi yang bagus, dan memberikan pengalaman kepada atlet yang lebih muda pada level Internasional, kontribusi libero 2 pada set ketiga sebagai berikut: error recive servis satu kali, lima kali recive servis bagus mudah di toss, dua kali cover smash, dan dua kali melakukan dig defense, satu kali pasing bawah. Set ketiga dimenangkan olah tim nasional bola voli putra Indonesia dengan skor: 25 - 17. Tim nasional bola voli Indonesia putra berhasil meraih medali emas pada SEA GAMES 2019 Philipina dengan mengalahkan tuan rumah Philipina dengan skor 3 - 0. Pelatih tim nasional Indonesia mendatangkan dari China.

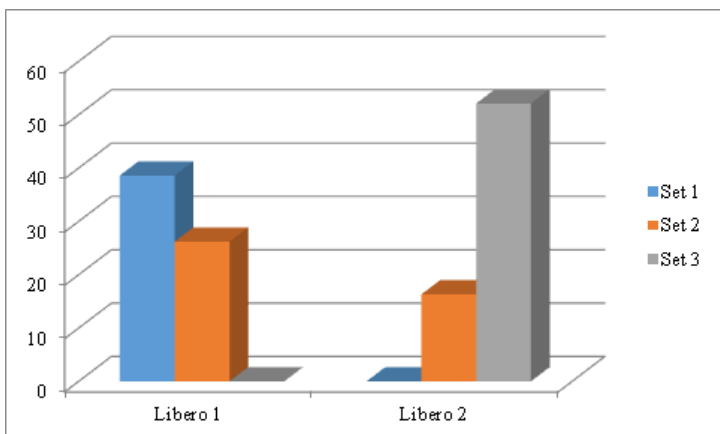

Gambar 1. Kontribusi kemampuan libero tim nasional Indonesia

Berdasarkan hasil penelitian diperoleh hasil bahwa kemampuan libero dalam recive servis, dig, cover dan toss merupakan kemampuan utama yang masing-masing memiliki kontribusi dan level tingkatan yang berbeda-beda. Kontribusi utama yang diberikan oleh libero untuk kemenangan tim adalah: kemampuan recive servis, dig, cover dan toss.
Kemampuan recive servis sangat dibutuhkan tim untuk memulai sistem serangan, dengan recive bola pertama yang baik maka variasi serangan dapat dilakukan oleh setter, sehingga smasher akan sangat terbantu dalam melakukan smash dengan blok yang terpecah fokus dan konsentrasi bloknya. Seperti pendapat (Waite: 2009) bahwa kunci utama dari recive servis adalah menerima bola dari servis dengan sasaran bola naik di tengah atas garis serang lapangan melambung dan mudah dilakukan toss oleh setter ke smasher, dan pemain yang memiliki recive servis yang bagus hendaknya membantu pemain yang lemah dalam recive servis.

Kemampuan dig yang diperoleh oleh libero akan menambah kesempatan untuk melakukan counter attack atau serangan balik ke lawan. Sedangkan kontribusi dig yang dilakukan oleh libero adalah mendapatkan defense dari serangan lawan dengan hasil bola yang bagus atau masih bisa diolah oleh setter untuk melakukan serangan balik ke lawan. Alasan di balik kemampuan dig yang akurat dalam bola voli sederhana, yaitu membuat tim untuk serangan yang kuat daripada kemungkinan mengirim bola keluar lapangan dan lawan menerima poin (Ackerman, 2014). Sudut di mana bola voli mengenai bola melengkung adalah penting (Kelling: 2007). Jika bola dipukul pada sudut yang kurang dari 80 derajat ke tubuh, lebih cenderung mendorong ke depan daripada ke atas (Lenberg, 2007).

Kemampuan cover yang dilakukan oleh libero diharapkan akan mendapatkan kesempatan ulang untuk melakukan serangan berikutnya, dimana serangan pertama berhasil dibendung blok lawan, atau serangan lawan yang berupa tip smash atau smash yang penempatan pelan, dapat diantisipasi libero. Dalam melakukan cover smash memerlukan posisioning yang bagus oleh libero atau setiap pemain. Kedisiplinan dalam cover ini sangat rendah sehingga sulit bagi atlet untuk disiplin dalam bergerak seperti air dalam permainan dalam artian mengalir dari posisi menyerang transisi dan bertahan. Defense yang baik dengan menggunakan cover sebagai salah satu caranya tidak hanya bertujuan agar bola tidak jatuh di lapangan kita, namun juga bisa untuk serangan balik ke lawan (Barth and Linkerhand: 2006).

Kemampuan toss oleh libero ke smasher sangat dibutuhkan dan tingkat kesulitanyya paling tinggi. Kemampuan mengumpan oleh libero ini dapat menggunakaan satu tangan, dua tangan, baik dengan pasing atas atau pa- 
sing bawah. Kemampuan toss bola ini harus dikuasai secara efektif oleh seluruh pemain dalam tim (Lendberg: 2006). Untuk melatih kemampuan toss ini adalah salah satunya dengan bermain atau umpan ke arah yang bervariasi (Barth and Heucert: 2005).

\section{SIMPULAN}

Kesimpulan dalam penelitian ini bahwa kontribusi kemampuan libero sangat menentukan dalam keberhasilan tim dalam melakukan serangan maupun bertahan. Pemain lain juga harus memberikan kontribusi baik recive servis (khususnya open hitter/open spiker), dan dig bagi seluruh pemain, cover smash dan blok, dan toss oleh seluruh pemain. Kontribusi kemampuan libero dalam skill: recive servis, dig, cover dan toss hendaknya lebih dari $50 \%$ dalam setiap set bermain. Persentase yang lain diharapkan akan disumbang oleh pemain lain dalam tim bola voli. Pelatih dalam memberikan latihan untuk libero dengan kondisi sedekat mungkin dengan kondisi sebenarnya di lapangan. Kesalahan yang dilakukan libero di lapangan hendaknya diulang-ulang dibenahi dan diberikan solusi atau pembetulan baik konsep maupun teknik. Libero dua orang sangat direkomendasi sebisa mungkin berbeda karakternya antara bagus dalam recive servis, cover, dig dan toss, harapannya akan bisa digunakan dalam situasi sesuai kebutuhan tim.

\section{DAFTAR PUSTAKA}

Ackerman, J. (2014). Girls Volleyball. ABDO.
Bach, G. (2009). Coaching volleyball for dummies. Canada: Wiley Publishing.

Barth, K; \& Heuchert. (2005). Learning volleyball. UK: Mayer \& Mayer Sports.

Barth, K; \& Linkhand, A. (2006). Training volleyball. UK: Mayer \& Mayer Sports.

Clemens, T \& McDowell, J. (2012). The volleyball drills book. USA: Human Kinetics.

Hebert, M. (2014). Thingking Volleyball. US: Human Kinetics.

Keeling, J. (2007). The Dig Tips for Keeping the Volleyball in Play. http://www.sportinglife360.com/index. $\mathrm{php} /$ the-dig-tips-for-keeping-the-volleyball-inplay-4-62113/.

Lenberg, K. (2006). Volleyball skills and drills. USA: Human Kinetics.

Lenberg, K. (2007). Preparing for the Perfect Pass. American Volleyball Coaches Association,

McKeever, M; Came, F; Smith, N; \& Handford, C. (2018). Volleyball. England: English Volleyball Association with Royal Navy.

Merghes, P.E; \& Gradinaru, S. (2014). Comparative analysis of the "libero" in great performance volleyball. Timisoara Physical Education and Rehabilitation Journal. Volume 6. Issue: 12. DOI: 10.2478/ tperj-2014-0024.

Merrett, H. (2004). Winning volleyball skills. Http://WinningVolleyballSkils.com.

Mesquita, I; Manso, F.D; \& Palao, J.M. (2007). Defensive participation and efficacy of the libero in volleyball. Journal of Human Movement Studies Vol. 52 No 2.

Miller, B. (2005). The volleyball handbook. USA: Human Kinetics.

Rentero, L; Joao, P.V; \& Moreno, M.P. (2015). Analysis of the libero's influence in different match phases in volleyball. Revista International de Medicina y Ciencias de la Actividad Fisica y el Deporte vol. 15 (60) pp. 739-756.

Roque, E. \& Hansen, J. (2012). Volleyball coaching manual. USA: LA84 Foundation.

Schmidt, B. (2016). Volleyball: steps to success. USA: Human Kinetics.

Waite, P. (2009). Aggressive volleyball. USA: Human Kinetics. 